\title{
An approach for performing a successful computed tomography colonography examination
}

\author{
Author: \\ Joel H. Bortz ${ }^{1}$ \\ Affiliation: \\ ${ }^{1}$ LSG Imaging, Santa Monica, \\ United States of America \\ Correspondence to: \\ Joel Bortz \\ Email: \\ joelbortzmd@gmail.com \\ Postal address: \\ 13031 Villosa Place, \\ Apartment 141, Playa Vista, \\ California 90094, United \\ States of America \\ Dates: \\ Received: 13 Mar. 2014 \\ Accepted: 17 Aug. 2014 \\ Published: 01 Dec. 2014 \\ How to cite this article: \\ Bortz, JH. An approach for \\ performing a successful \\ computed tomography \\ colonography examination. \\ S Afr J Rad. 2014;18(1); \\ Art. \#607, 11 pages. http:// \\ dx.doi/org/10.4102/sajr. \\ v18i1.607

\section{Copyright:} \\ (C) 2014. The Authors. \\ Licensee: AOSIS \\ OpenJournals. This work \\ is licensed under the \\ Creative Commons \\ Attribution License.
}

Read online:
Computed tomography colonography (CTC) is a minimally invasive, fast, safe and accurate screening examination for colorectal cancer. It also allows evaluation of structures outside the colon. A successful CTC examination requires good bowel preparation, adequate patient hydration, tagging agents, the use of automated carbon dioxide insufflation, and correct positioning for two view and additional view scans. Knowledge of polyp morphology and measurement of polyps are important when interpreting 2D or 3D scans.

\section{Introduction}

Colorectal carcinoma (CRC) is the third most common cancer in the United States of America (USA), and the second most common cause of death from cancer. The latest CRC statistics for new cases in the USA is expected to decrease to 136830 from the previous estimate of more than 143000 cases in 2012. ${ }^{1,2,3}$ The number of deaths in 2014 is expected to decrease to 50310 from the previous figure of more than 52000 deaths per year. ${ }^{1,2,3}$ Most colon cancers, apart from inherited genetic disorders, such as hereditary non-polyposis colorectal cancer, arise from a pre-existing polyp which develops over a period of $10-15$ years into a cancer. ${ }^{4}$

Colon cancer screening is recommended every five years from the age of $50,{ }^{2}$ but colorectal examinations are a contested terrain of diagnostic imaging versus optical colonoscopy (OC). This contested terrain has shifted since the introduction of newer imaging technologies, such as computed tomography colonography (CTC), ${ }^{2,5,6}$ which is widely recognised as a highly sensitive and specific test for identifying polyps and cancer in the colon. ${ }^{2,5}$

To the best of the author's knowledge, no article on how to perform a CTC has been published to date in South Africa. CTC was not included as a screening test for CRC in a 2011 survey of a privately insured population for a single insurer across all nine South African provinces. ${ }^{7}$ CRC was the fourth leading cancer in South Africa in $2004 ;{ }^{8}$ more recent CRC statistics are not available. Although double-contrast barium enema (DCBE) is not as effective as CTC, and is rapidly becoming an obsolete technique, ${ }^{9}$ it remains widely practised in South Africa and elsewhere in the world. Fairly recent studies show the sensitivity of DCBE at approximately 50\% for polyps $>10 \mathrm{~mm}^{10}$ whereas for CTC it is $97 \%$ for polyps $>10 \mathrm{~mm} \cdot{ }^{11}$

An important advantage of CTC over OC is the former's ability to visualise the intra-abdominal and pelvic organs. The majority of findings will ultimately prove to be of little or no clinical significance. ${ }^{12,13}$ However, in approximately $10 \%$ of cases, significant pathology may be identified, such as early cancers of the kidney and ovary as well as abdominal or pelvic lymphadenopathy in underlying lymphoma. Abdominal aortic aneurysms $>5 \mathrm{~cm}$ in transverse diameter may be detected incidentally. ${ }^{12,13}$ Visualisation of such pathology is not possible with OC or DCBE. CTC is less invasive, with minimal complications. ${ }^{14}$

OC holds inherent risks related to sedation and potential bowel perforation. ${ }^{15} \mathrm{CTC}$ is a much safer form of study than OC as no sedation is required and the risk of perforation is significantly less, with only sporadic cases of perforation recorded. ${ }^{16}$ Perforation is higher in diagnostic studies than with screening procedures, particularly when stenosing lesions are present. Certain precautions are recommended to maintain a low perforation rate, namely (1) the use of a soft rubber catheter as opposed to the large plastic barium enema tube; (2) constant infusion of carbon dioxide $\left(\mathrm{CO}_{2}\right)$ under monitored pressure; and (3) not performing the study after a recent full thickness biopsy. ${ }^{16}$

The aim of the present paper is to present an approach for a successful CTC examination, ensuring the performance of a high-quality study that allows accurate interpretation by a general diagnostic radiologist. ${ }^{17}$ The author has performed more than 5200 CTCs in the USA over the past 10 years. Bowel cleansing in CTC for screening patients is highlighted. In addition, CTC 
following an incomplete OC is discussed. Interpretation of images is also briefly discussed.

\section{CTC protocol}

There are two critical components to achieving a successful CTC: an adequately cleansed bowel and good distension of the colon with $\mathrm{CO}_{2}$. There are many ways to perform CTC, but it is advisable to choose a method from an institution that has published evidence of consistently producing outstanding results, and to then follow the published recommendations. The author has adopted the technique used by Drs Pickhardt and Kim from the University of Wisconsin (USA), ${ }^{18}$ who have shown the importance of: bowel preparation; the use of $\mathrm{CO}_{2}$ instead of room air; 3D visualisation using approved software; and a multiple detector computed tomography (MDCT) scanner. A deficiency in any of these factors can cause a poor CTC result.

The following points are embedded in the CT protocol used by the author: adherence to CTC indications (Table 1); informed consent; adequate patient hydration; cathartic and tagging agents; and the use of $\mathrm{CO}_{2}$ (Table 2)

\section{Colonic preparation}

Bowel preparation is controversial in terms of patients' compliance..$^{19,20}$ There are a variety of bowel preparations available, including magnesium citrate, a cathartic bowel preparation. In addition, tagging agents, such as $250 \mathrm{ml}$ of
$2.1 \% \mathrm{w} / \mathrm{v}$ Readi-Cat and $60 \mathrm{ml}$ diatrizoate (gastrografin), are used. The barium tags the stool and the gastrografin tags the residual fluid (Table 3).

For a successful examination, bowel preparation should comprise a well-established CTC standard protocol. ${ }^{6}$ Bowel preparation commences the day before the scheduled examination; a 24-hour liquid diet is required (Table 3 presents a list of permitted liquids), with nil per mouth from midnight. If the patient has had breakfast in error, another CTC appointment must be arranged. It is important for the patient to be fully briefed on all requirements when a CTC is booked. An appropriately trained person must carefully explain to the patient the importance of adhering to a liquid diet and taking the bowel preparation medication at the correct times (steps 1 and 2 in Table 3). The times to take the medication in these steps, and the tagging agents, must be included on the labels on the bottles.

The patient must be informed that onset of bowel action is variable: it may occur after 30 minutes or for up to 4 hours. Tagging is an integral part of the colonic preparation (steps 3 and 4 in Table 3). The patient should be warned of the unpleasant taste of gastrografin; dilution in a flavoured drink lessens the unpleasant taste.

Notably, barium does not adhere to the colonic wall, but rather coats the surface of polyps, making them more conspicuous and easier to diagnose.,17 This effect may reduce the false-positive rate on CTC. Gastrografin has a

TABLE 1: Indications and contra-indications for CTC.

\section{Indications CTC \\ Screening of asymptomatic adults at average risk for colorectal cancer}

Following failed or incomplete optical colonoscopy

Asymptomatic patients with a positive family history

All patients on anticoagulant therapy needing colorectal screening

Surveillance following resection of polyps or cancer

Surveillance of unresected $6 \mathrm{~mm}-9 \mathrm{~mm}$ polyps detected at CTC

Unexplained GI bleeding iron deficiency anaemia

Unexplained GI symptoms

CTC, computed tomography colonography.

Contra-indications CTC
Active inflammatory bowel disease (e.g. Crohn's disease; ulcerative colitis)
Routine follow-up of inflammatory bowel disease
Recent deep endoscopic biopsy or polypectomy - wait 4-6 weeks before performing a
CTC
Known or suspected colonic perforation
Any symptomatic acute colitis (e.g. patient has abdominal pain, diarrhoea with passage
of blood or mucus)
Colon containing inguinal hernia
Acute diverticulitis - wait six weeks post conservative treatment before performing a
CTC
Acute diarrhoea
Pregnancy
Hereditary polyposis or non-polyposis cancer syndrome
Known or suspected bowel obstruction

Known or suspected bowel obstruction

TABLE 2: Room air versus $\mathrm{CO}_{2}$

Room air

Free

Good distension

Results in abdominal cramping and post-procedural distension

Must be passed rectally

Air administration done in blind fashion
$\mathrm{CO}_{2}$

Cheap: a \$US19 cylinder can be used for approximately 350 CTCs

Constant infusion

Rapidly absorbed across the colonic mucosa and exhaled

No post-procedural cramping or distension

No manual pumping

Accurate pressure and volume of $\mathrm{CO}_{2}$ recording

Better distension with less effort

Rapid decompression of the colon following CTC, with less discomfort

and distension

Automated delivery allows a constant low-pressure infusion to maintain colonic distension 
TABLE 3: Patient preparation

\begin{tabular}{|c|c|c|}
\hline Ensure clean bowel & Preparation day & Day of CTC \\
\hline \multicolumn{3}{|l|}{ Hydration } \\
\hline $\begin{array}{l}\text { Patient to drink } 3-4 \text { litres ( } 4 \text { quarts) of clear liquid a day } \\
\text { before CTC. (red liquid to be avoided, e.g. cranberry } \\
\text { juice, red Jell-O) } \\
\text { Tip: If liquid can be seen through and there is nothing } \\
\text { floating in it, then it may be consumed }\end{array}$ & $\begin{array}{l}\text { - No solid foods day before the CTC and prior to CTC } \\
\text { - Adequate hydration to be maintained: clear liquid } \\
\text { throughout the day to be consumed until midnight, } \\
\text { thereafter nil per mouth } \\
\text { - Diabetic patients to test blood glucose level more } \\
\text { often and to drink clear liquid that contains sugar if } \\
\text { less than } 70 \mathrm{mg} / \mathrm{dl}\end{array}$ & $\begin{array}{l}\text { - Nil per mouth until completion of CTC } \\
\text { - Patients on daily medications may take as prescribed } \\
\text { with small sips of water }\end{array}$ \\
\hline
\end{tabular}

\section{Approved clear liquids}

Tea/coffee; iced tea; apple/white; grape/white cranberry - Patients on medications to take them 1 hour before juice; lemonade; Powerade; soda/diet soda; coconut water; vitamin water; Jell-O/popsicles; clear broth or consommé

\section{Not approved}

Orange juice; tomato juice; grapefruit juice; prune juice; red liquids

or 1 hour after taking the magnesium citrate

NB: No solid foods day before CTC. Fasting after midnight

Bowel preparation kit

Bisacodyl tablets $5 \mathrm{mg} \times 2$

Magnesium citrate $2 \times 296 \mathrm{ml}$ bottles

Barium sulphate $2.1 \% \mathrm{w} / \mathrm{v}(250 \mathrm{ml})$ to tag remaining stool

Diatrizoate meglumine (gastrografin) $(60 \mathrm{ml})$ to tag

remaining fluid

Step 1:

At 11h00: Bisacodyl tablets to be taken with 1 glass (200 $\mathrm{ml} ; 8$ ounces) clear liquid.

Step 2:

At 14h00: one bottle $(296 \mathrm{ml}$ ) of magnesium citrate to be swallowed, followed by at least 4-6 cups clear liquid.
lo be swall

Step 3:

At 17h00: $250 \mathrm{ml}$ barium sulphate to be drunk, followed by the remaining bottle of magnesium citrate.

Step 4:

At 20h00: $60 \mathrm{ml}$ of undiluted diatrizoate (gastrogafin)

to be swallowed OR can be mixed with 1 glass of clear

liquid; the entire amount must be swallowed (not

necessary to drink this quickly).

CTC, computed tomography colonography; OC, optical colonoscopy.

dual action: (1) it stains the residual fluid white, aiding in 2D evaluation of submerged polyps; and (2) it emulsifies the stool adherent to the bowel wall, causing a secondary catharsis. ${ }^{6}$

It is sensible to shift to polyethylene glycol solution (PEG: Klean-Prep) for the extremely small percentage of patients who are in poor health owing to cardiac or renal disease, or hypertensive patients taking angiotensin-convertingenzyme (ACE) inhibitors to avoid fluid or electrolyte shift. Klean-Prep has an unpleasant taste, and consumption of a large volume is necessary; consequently, patients do not usually adhere strictly to its correct use.

\section{Positioning and introduction of $\mathrm{CO}_{2}$}

Before commencing a CTC examination, the patient is sent to the restroom as the rectum must be emptied of any residual fluid. Figure 1 is a synopsis of the CTC technique described below. The patient is positioned feet first in a left lateral position in the scanner. A disposable soft rubber rectal catheter is then gently inserted into the rectum and the balloon is insufflated with $20 \mathrm{cc}$ of air employing a 3-way connection (Figure 2). The hard plastic tube previously used for DCBE is employed only in rare cases. Use of a soft rubber catheter reduces risk of perforation.

It is essential to check that there is sufficient $\mathrm{CO}_{2}$ in the cylinder before commencing a CTC. The $\mathrm{CO}_{2}$ insufflator (PROTOCO $\mathrm{L}-$ Bracco) is switched on and the pressure set to $15 \mathrm{mmHg}$ to enable the $\mathrm{CO}_{2}$ to gently flow at low pressure into the descending colon until one litre of $\mathrm{CO}_{2}$ has been introduced (Figure 3). At this point, turn the patient onto the right side to fill the proximal transverse and ascending colon. The pressure at this stage may be increased to $20 \mathrm{mmHg}$ to distend the colon. When the volume reaches two litres, return the patient to the supine position and commence scanning. For all scans, instruct the patient to inhale, then exhale, and suspend breathing during scanning. Scanning is performed in exhalation as this elevates the diaphragm and allows the colon and flexures to expand. The first breath hold (5 seconds) allows acquisition of the scout film. Once this film is reviewed, inform the patient that the full supine scan of the abdomen will commence.

Next, the $\mathrm{CO}_{2}$ insufflator is switched off whilst the patient is turned prone. This is done because elderly and obese patients may have trouble turning prone and the intracolonic pressure rises rapidly, often above $60 \mathrm{mmHg}$, thereby triggering the machine alarm. Some radiologists use the deflation manoeuvre after completion of the supine scan by emptying the rectum of air and then re-inflating for the prone scan; this reduces the incidence of pain..$^{21}$ From time to time, it may not be possible for some patients to turn into the prone position, and a decubitus view will be required instead. Ensure that, when scanning in the prone position, a pillow placed under the patient's chest does not impinge on the abdomen.

With the patient in the prone position, (1) the balloon is deflated to visualise internal haemorrhoids, if present (Figure 4); and (2) the $\mathrm{CO}_{2}$ insufflator is switched on and 
Before commencing the procedure, send patient to restroom to empty rectum. Place patient in a lateral position.

$\downarrow$

Insert soft tube in rectum. Blow up balloon with $20 \mathrm{cc}$ air $\downarrow$

Open rectal bag clip to drain rectum, then re-clamp.

$\mathrm{CO}_{2}$ introduced gently at low pressure $(15 \mathrm{mmHg})$ until 1 litre is introduced. $\downarrow$

Turn patient prone, then onto right side.
$\downarrow$
Gradually increase pressure to $20 \mathrm{mmHg}$.

When 2 litres are introduced, the patient is ready for scanning. $\downarrow$

Patient placed supine and positioned in the scanner.

$$
\text { Scout and supine study performed. }
$$

Switch off $\mathrm{CO}_{2}$ while turning patient into prone position (Intracolonic pressure can $\uparrow$ to $>50 \mathrm{mmHg}$ in, for example, obese/elderly when turning.)

$$
\downarrow
$$

Deflate rectal balloon in order to visualise haemorrhoids, if present. $\downarrow$

Switch on $\mathrm{CO}_{2}$ and then do 2 nd scout as well as prone study. $\downarrow$

When prone scan is completed, switch off $\mathrm{CO}_{2}$ For patient comfort, open the rectal bag clip to drain rectum. Re-clamp.

Turn patient into lateral decubitus (RLD) position while waiting for images to reach 3D workstation.

If portions of bowel are not distended, do RLD scans.

First introduce more $\mathrm{CO}_{2}$ ( 1 litre) as rectum has been emptied of gas.

Switch off gas while waiting for images to be processed.

If RLD scan is inadequate, turn patient into LLD. Re-introduce a further litre of $\mathrm{CO}_{2}$. $\underset{\text { Scan. }}{\downarrow}$ $\downarrow$

Turn off $\mathrm{CO}_{2}$ and check images.

(NB. Total amount of $\mathrm{CO}_{2}$ varies from 2.5 litres to 4 litres. Can go up to 10 litre.)

Remove rectal tube and send patient to restroom.

FIGURE 1: Schematic presentation of computed tomography colonography (CTC) technique.

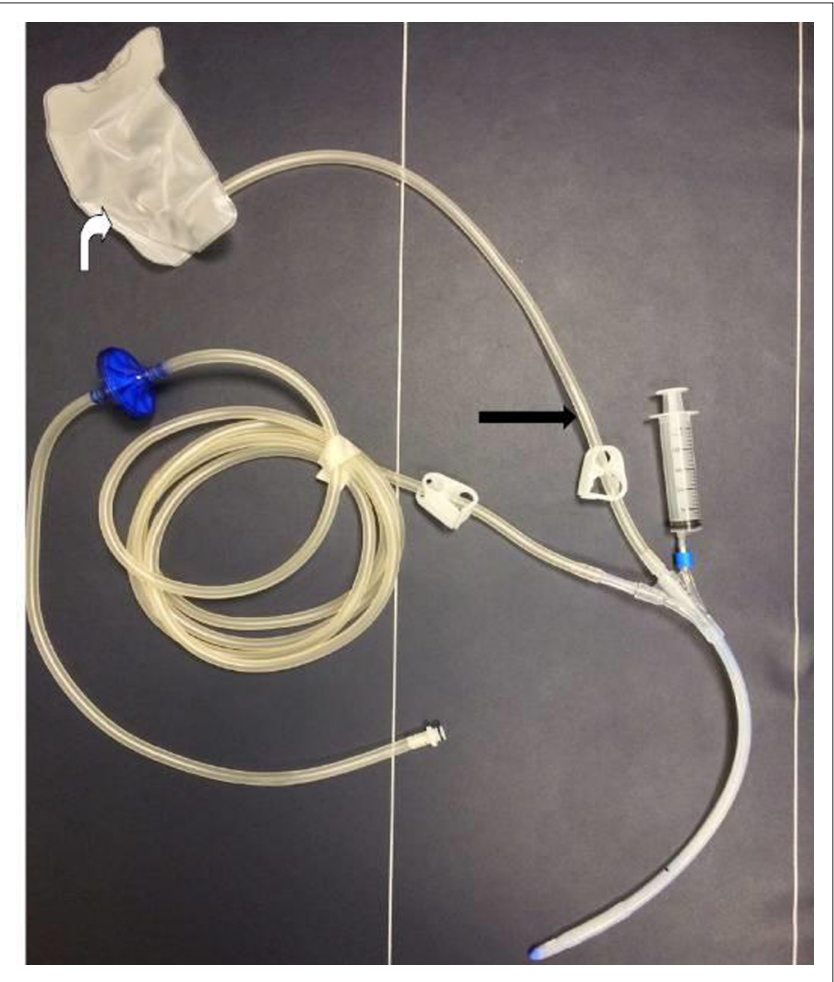

FIGURE 2: Three-way connection. Rectal drainage (black arrow). Rectal drainage bag (white arrow).

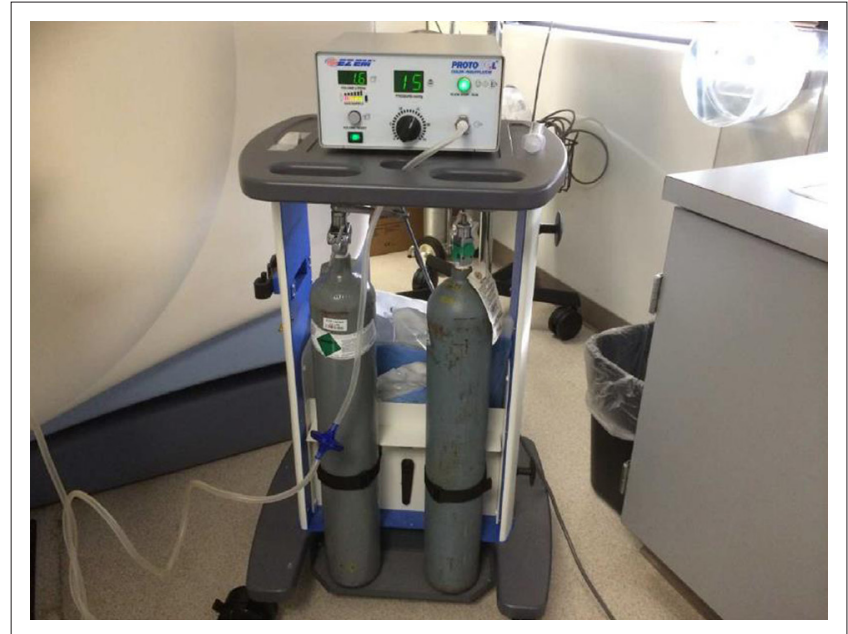

FIGURE 3: The $\mathrm{CO}_{2}$ insufflator.

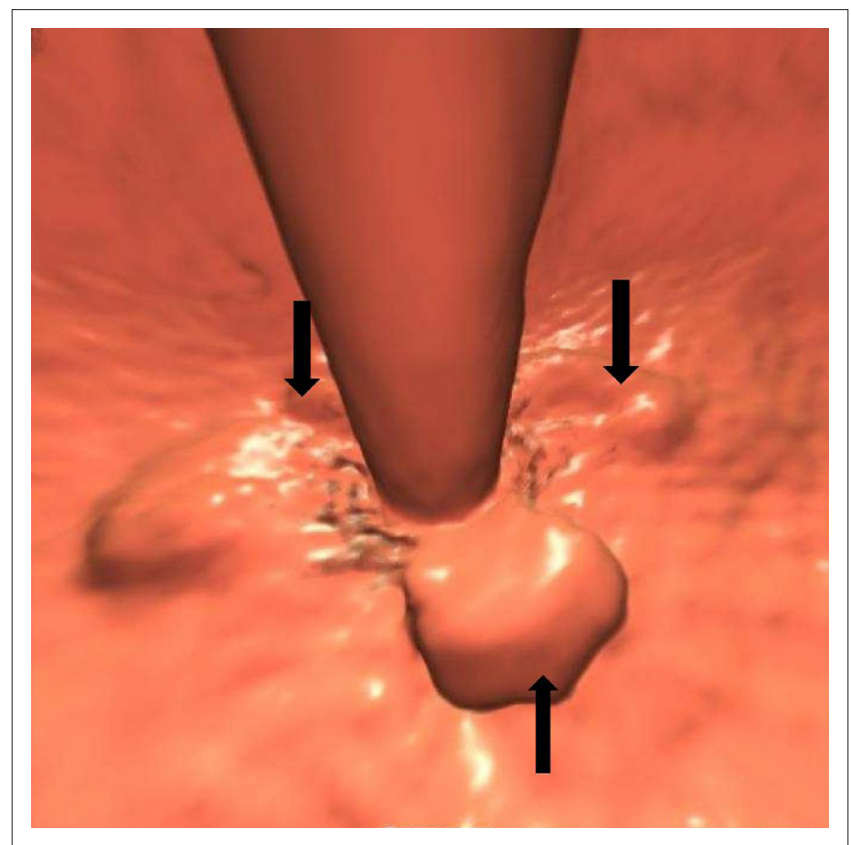

FIGURE 4: Large internal haemorrhoids (arrows) visualised when the balloon is deflated.

the patient positioned for scanning. A scout film is taken on exhalation and breath hold. The scan usually takes 12 seconds. When the prone scan is completed, the insufflator is switched off and the clip of the rectal bag is opened to empty the rectum. This manoeuvre gives immense relief to the patient, who is turned into the right lateral decubitus (RLD) position while the images are examined by the radiologist. On average, the acquisition and assessment of a two-view CTC study takes no more than five minutes. CTC requires on average between 15 to 20 minutes' room time.

Should areas of poor distension be identified, in particular the sigmoid colon in cases of diverticular disease, the patient is ready to be scanned in the RLD position. The insufflator is switched on again, introducing a litre of $\mathrm{CO}_{2}$, as the rectum was previously emptied when the bag was unclamped. After the $\mathrm{CO}_{2}$ has been introduced, scanning on breath hold can recommence. Whilst waiting for the images to be processed, 
the $\mathrm{CO}_{2}$ is switched off. In the rare case where the RLD is unable to distend the appropriate area, the patient is turned into the left lateral decubitus (LLD) position. The $\mathrm{CO}_{2}$ is switched on and the patient re-scanned.

It is important to appreciate the benefits of using an insufflator. The intracolonic pressure is constantly monitored, as indicated on the second dial on the $\mathrm{CO}_{2}$ insufflator. The maximum pressure is $25 \mathrm{mmHg}$, which prevents the risk of perforation. By comparison, a standard handheld air-bulb insufflator cannot determine the intracolonic pressure or the volume of gas introduced. According to Sosna and colleagues, ${ }^{22}$ each puff of the handheld device will introduce approximately $40 \mathrm{cc}$ of air; at least 50 puffs will be required to introduce two litres of air. Of importance is that the pressure at which the air is introduced is unknown. The danger of perforating the bowel under these circumstances far exceeds that of the gentle measured pressure and volume attained with a $\mathrm{CO}_{2}$ insufflator.

Carbon dioxide is rapidly resorbed compared with room air, which results in reduced abdominal distension and pain. ${ }^{23,24}$ It may, however, cause bloating for a short period. If a patient does complain of pain early on in the procedure, it is important to immediately check the inguinal regions for possible bowel herniation (Figure 5a and Figure 5b). If this is negative, the most likely cause is underlying diverticular disease.

Adequate distension does not imply complete distension of all segments in all cases. Cases of established diverticulosis tend to cause areas of non-distension. Additional views are frequently required to open the sigmoid area satisfactorily.

\section{Do spasmolytics have a role in CTC?}

Glucagon is rarely used as a spasmolytic in the USA because of cost and the side-effects of nausea and vomiting. Buscopan (hyoscine butylbromide) is not available because it has not been approved by the USA's FDA (Food and Drug Administration). ${ }^{6}$ In Europe and South Africa, Buscopan is often used to relax the bowel for good distension. However, it may relax the ileo-caecal valve and result in the small bowel filling with air. Occasionally the valve may be incompetent without the use of a spasmolytic. Carbon dioxide refluxes into the small bowel and it may rapidly reach the stomach (Figure 6). When this occurs, the patient complains of nausea and usually breaks into a sweat. It is essential to instruct the patient to burp, causing immediate relief.

\section{Role of tagging}

Apart from tagging stool, barium also lightly covers a polyp, thereby making it more conspicuous on $2 \mathrm{D}$ viewing. A useful tip is to scroll carefully through the polyp to assess whether there is soft-tissue thickening underlying the barium. A recent paper ${ }^{6}$ underscores that contrast coating of a flat polyp can act as a marker for detection (Figure 7).
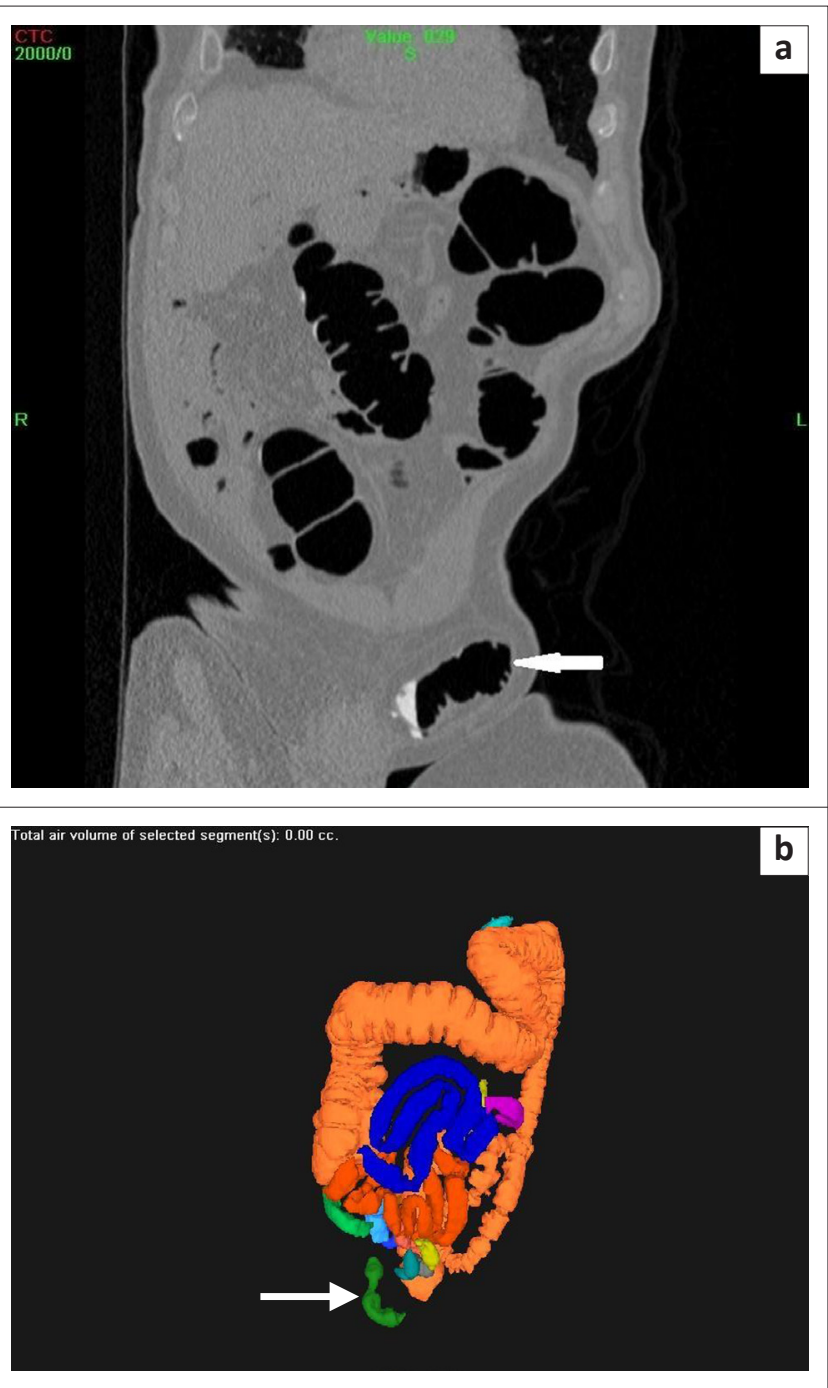

FIGURE 5: (a) Herniation of sigmoid colon in left inguinal region (arrow). (b) Small bowel in right inguinal region (arrow).

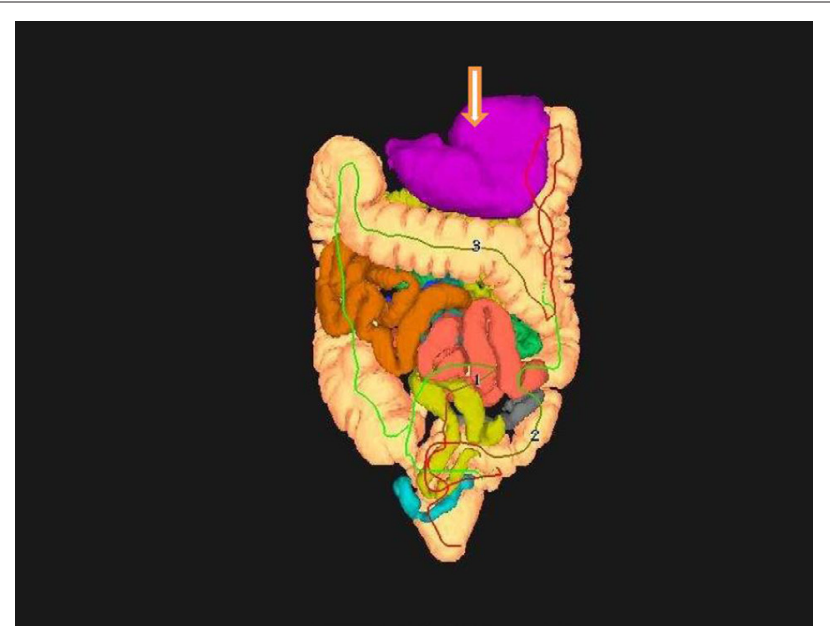

FIGURE 6: Air in stomach (arrow).

There are clues that allow differentiation between a polypoidal lesion and stool: $2 \mathrm{D}$ and $3 \mathrm{D}$ views are complementary. The former is the most useful method for making the distinction. Stool may be covered by barium and frequently contains small bubbles of air, giving it a 
heterogeneous appearance (Figure 8). Air within stool is not identified on 3D viewing. Most typically, stool will move to the opposing wall when the patient is turned from the supine to the prone position (Figure 9). A sessile polyp does not move with postural change. However, beware of the pedunculated polyp on a long stalk which may move with postural change (Figure 10).

\section{Should $40 \% \mathrm{w} / \mathrm{v}$ barium be used in CTC?}

Use of the relatively high-density barium has several disadvantages and is therefore not recommended for use in CTC examinations. If $40 \% \mathrm{w} / \mathrm{v}$ barium is used for a CTC

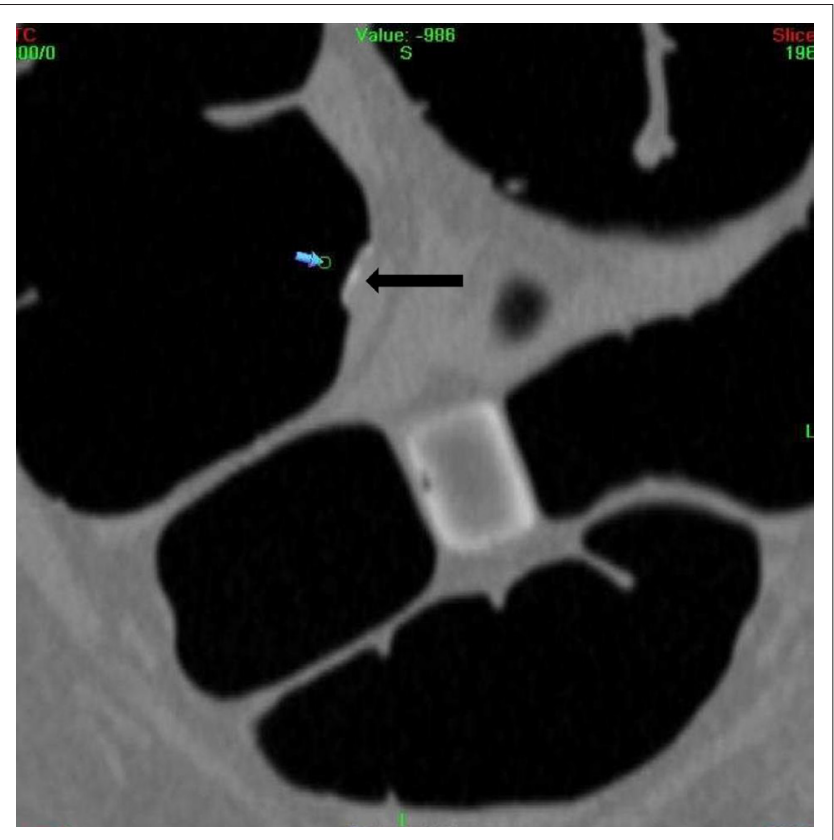

FIGURE 7: Barium covering flat polyp (black arrow)

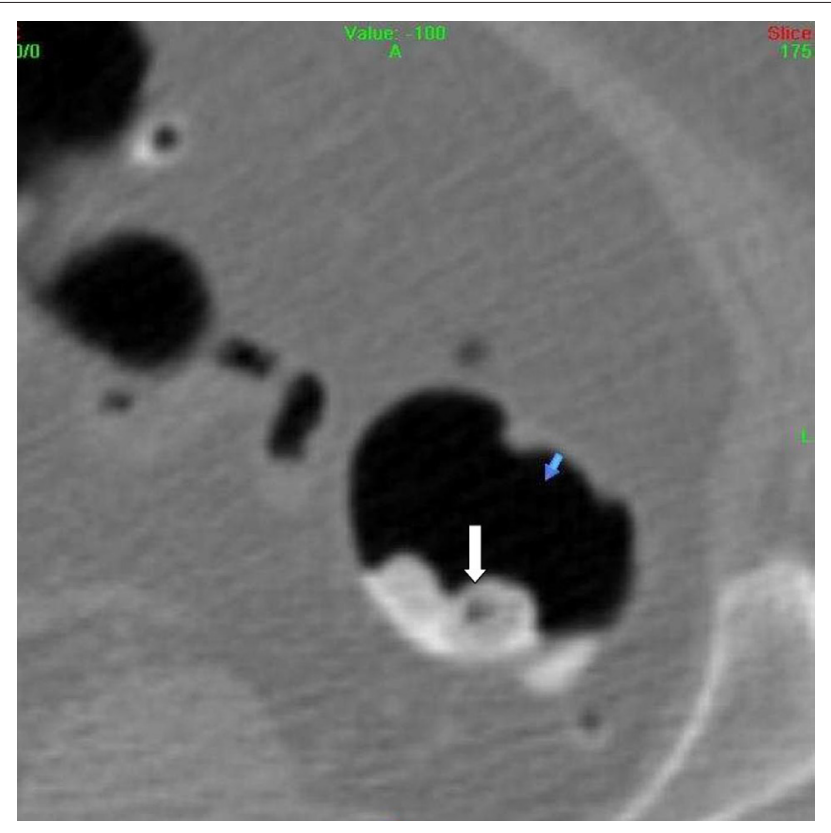

FIGURE 8: Air in stool (arrows).

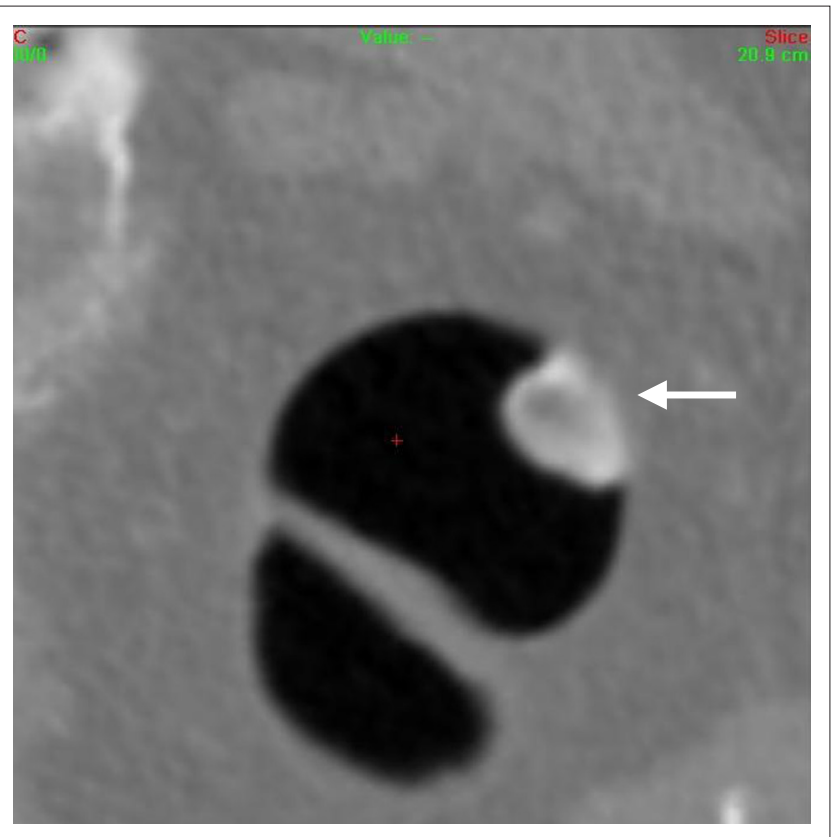

FIGURE 9: Stool moved to the opposite wall in the prone position.
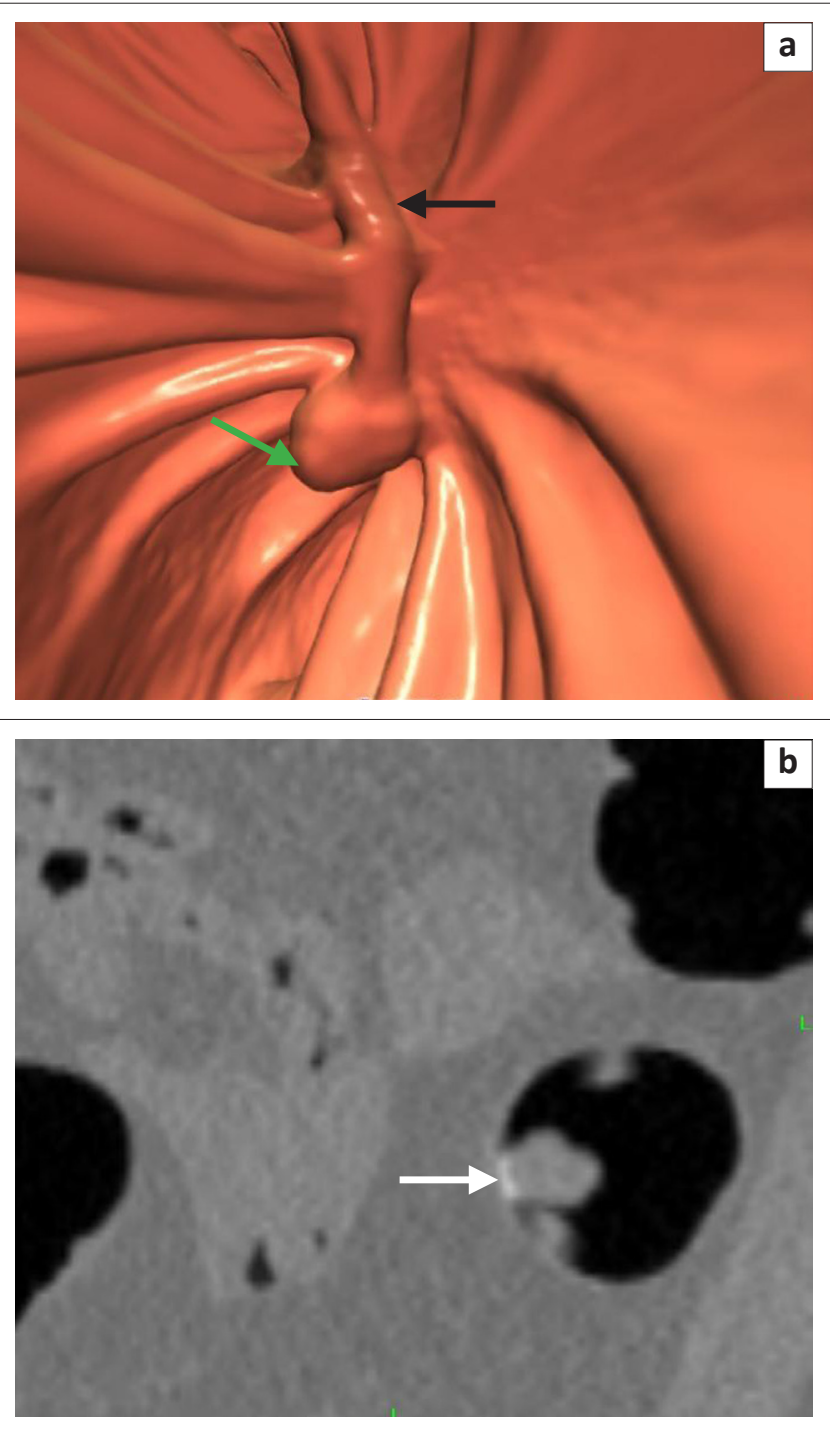

FIGURE 10. (a) Pedunculated polyp on long stalk in supine position (green arrow = head and black arrow =stalk). (b) Pedunculated polyp on medial wall (arrow). 
study, this does not include a cathartic bowel cleansing so it is not possible to perform a same-day OC. ${ }^{17}$ Electronic cleansing is not routinely performed because it may cause a large number of artifacts that could make interpretation difficult. Part of the surface mucosa may be electronically removed and could result in missed lesions.

\section{CTC protocol: Radiation dose considerations}

It is feasible to perform CTC using a 4-slice and above scanners. ${ }^{25}$ Currently, 16-slice scanners and above are recommended. Such scanners allow for a short breath hold during scanning but image quality is not improved. Sub-millimetre collimation is neither recommended nor used. Slice collimation is set at $1.25 \mathrm{~mm}$ with a $1 \mathrm{~mm}$ reconstruction interval. Tube potential is set for $120 \mathrm{kVp}$ which is raised to $140 \mathrm{kVp}$ for large patients. Reducing tube current (mA) reduces dose to the patient, in keeping with ALARA (as low as [is] reasonably achievable) principles. ${ }^{26}$ CT manufacturers have taken heed of increasing concerns about radiation dose, and have developed radiation reduction tools such as automated tube current modulation, automated tube potential and iterative reconstruction, in the latest generation scanners. ${ }^{27}$ With the introduction of tube current modulation, protocols can now concentrate on setting an appropriate noise level to minimise dose. A tube current modulation system is used (Smart mA, GE Healthcare) whereby the noise level is set at 30 for the supine study and 50 for the prone study, and the tube current range at $30 \mathrm{~mA}-300 \mathrm{~mA}$. This has yielded a $40 \%$ reduction of dose in the prone position with minimal degradation of 3D and 2D images. For MDCT scanners not equipped with a tube current modulation system, a technique with a tube current-time product in the range of $50 \mathrm{mAs}-75 \mathrm{mAs}$ usually suffices. ${ }^{28} \mathrm{~A}$ tube current-time is set between $50 \mathrm{mAs}-75$ $\mathrm{mAs}$ for those machines not equipped with a tube current modulation system. These protocols result in a median effective dose of $4.5 \mathrm{mSv}$ for both supine and prone studies: CTC is a low-dose examination. ${ }^{29}$

\section{Diagnostic CTC following incomplete OC}

Reasons for a failed OC might include older patients, female gender, colon length, number of acute angle bends and flexures, advanced diverticular disease, prior abdominal surgery, occlusive cancers, benign strictures, colon containing hernias, intestinal malrotation and poor bowel preparation. From a CTC perspective, this latter group of patients is the most challenging. They have predominantly been prepared for an OC using a 'wet' preparation, such as PEG, and not a 'dry' one as is favoured for CTC. In addition, these patients were not given preprocedural contrast or fluid tagging, making it more challenging to exclude falsepositives, such as stool adherent to the wall.

It is imperative to first exclude the possibility of an OCcaused colonic perforation before commencing with
CTC. There have been rare reports of colonic perforation at CTC, especially in patients with obstructive lesions. ${ }^{16}$ Approximately $50 \%$ of patients with colonic perforations do not have symptoms. To avoid possible medico-legal implications, a pre-procedure low-dose CT scan should be done prior to rectal catheter insertion. The technique used by the author comprises a $10 \mathrm{~mm}$ slice thickness at $10 \mathrm{~mm}$ intervals. ${ }^{30}$ The subsequent images are viewed by the radiologist and, if extra-luminal air is present, a CTC is not performed. The referring clinician is informed of this CT finding.

Hough et al. $^{30}$ reported a total effective dose of $0.9 \mathrm{mSv}$ for men and $1.2 \mathrm{mSv}$ for women in low-dose abdominopelvic CT to exclude perforation. Alternative techniques may be used, such as a slice through the upper, middle and lower abdomen. These increased gaps may be a trade-off for sensitivity. Professor P. Pickhardt (personal communication, May 2014) stated that low-dose CT is preferred to erect plain-film radiographs. According to Professor Pickhardt, the latter only excludes free air whereas most perforations have contained extra-luminal gas, retroperitoneally or intramural.

Before proceeding with a CTC, the radiologist must know whether a recent polypectomy or biopsy (superficial or deep) has been performed. Occasionally, with superficial biopsies, the $\mathrm{CO}_{2}$ may track sub-mucosally and result in pneumatosis coli. If a deep biopsy or polypectomy has recently been performed, it is advisable to wait at least four weeks before proceeding with the CTC to allow the mucosa to heal (see Table 1).

Patients would prefer a same-day CTC after a failed OC to eliminate the need for two separate bowel preparations. From a CTC standpoint, the examination tends to be suboptimal as tagging has not been performed. To overcome this limitation, $30 \mathrm{ml}$ of gastrografin is administered when the patient is fully awake and able to swallow. The patient is then turned onto the right side and kept in this position for two hours to empty the stomach. Gastrografin usually takes a minimum of two hours to travel through the colon. The patient is then scanned. This CTC technique results in moderate success because there is excess luminal fluid or streak artifacts from the dense residual contrast in the stomach, which degrades the quality of the study. Unfortunately, $30 \mathrm{ml}$ of gastrografin does not effectively tag residual faecal matter.

An option that is seldom adopted is to keep the patient on a liquid diet for a second day. Then $250 \mathrm{ml}$ of $2.1 \% \mathrm{w} / \mathrm{v}$ ReadiCat is taken at approximately 17h00, followed by $60 \mathrm{ml}$ gastrografin three hours later (at 20h00). No further laxatives are required, and the patient is scanned the following morning.

In view of CTC's efficacy, barium enema following incomplete OC should no longer be performed..$^{31}$ 


\section{Extracolonic findings}

CTC screening is usually performed in healthy asymptomatic individuals. The protocol also includes performing noncontrast scans of the pelvis and abdomen. An automatic retrospective reconstruction of the supine series of all patients is performed for evaluation of extracolonic findings. This consists of $5 \mathrm{~mm}$ sections at $3 \mathrm{~mm}$ intervals. It is important to remember that, when performing the prone series, there is often more coverage and certain lesions, such as those from lung cancer, may only be detected on prone imaging.

A classification of extracolonic findings has been devised (Table 4). ${ }^{18,32,33}$ The overall detection rate of unsuspected cancer is approximately one per 200 asymptomatic adults undergoing routine screening CTC, including about one invasive CRC per 500 cases, and one extracolonic cancer per 300 cases. $^{34}$

\section{Interpretation}

A successful CTC is not difficult to perform if the bowel is clean and the colon is well distended. There are two methods available to read the scans: $2 \mathrm{D}$ and 3D. Some proponents prefer using $2 \mathrm{D}$ as a primary approach with $3 \mathrm{D}$ reserved for problem-solving, whereas others prefer $3 \mathrm{D}$ as the primary method. ${ }^{2,35}$ There is consensus that readers need to be skilled in both interpretation methods. For 2D polyp detection, the window setting should be at a window width of 1500 and centred at 0 to $-200 .{ }^{18}$ Sessile polyps have a round or ovoid morphology and are of soft-tissue density. These should be visualised in both prone and supine scans as their position is not affected by postural change. Stool, on the other hand, does move as previously discussed. Air is often visible in the stool, giving it a heterogeneous appearance (Figure 8). As stated previously, one must beware the pedunculated polyp on a long stalk in terms of postural change (see Figure 10).

Pickhardt et al. maintain that primary 3D evaluation is preferable; they advocate the use of $2 \mathrm{D}$ for evaluation of polyp/stool differentiation. ${ }^{35}$ They maintain that this approach is easy, quick and extremely accurate. They conducted research on the accuracy of readers when using 2D compared with 3D. ${ }^{35}$ According to these authors, primary 2D CTC is less sensitive than primary 3D CTC for polyp detection in low-prevalence screening cohorts.

All current systems allow improved 3D fly-through. The author's preference is a primary 3D system, such as the Viatronix 3D system, but there are other options. The author's standard protocol is to perform supine and prone scans; additional views in the RLD and LLD may be required (Figure 1). Changing a patient's position by $180^{\circ}$ allows shifting of pooled liquid as well as movement of stool from one wall to the opposite wall. The field of view (FOV) is set at $120^{\circ}$ to provide good visualisation of the mucosa and folds. The folds in the left colon (anal verge to splenic flexure) are usually circular; in the right colon (caecum to splenic flexure) they become triangular (Figure 11 and Figure 12).

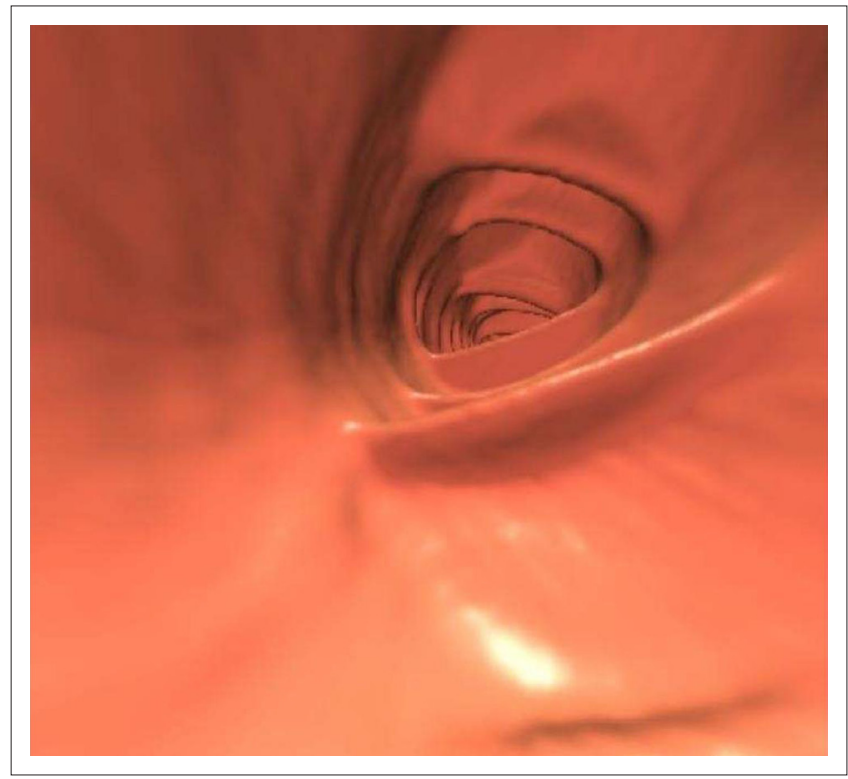

FIGURE 11: Left colon has circular folds (anal verge to splenic flexure).

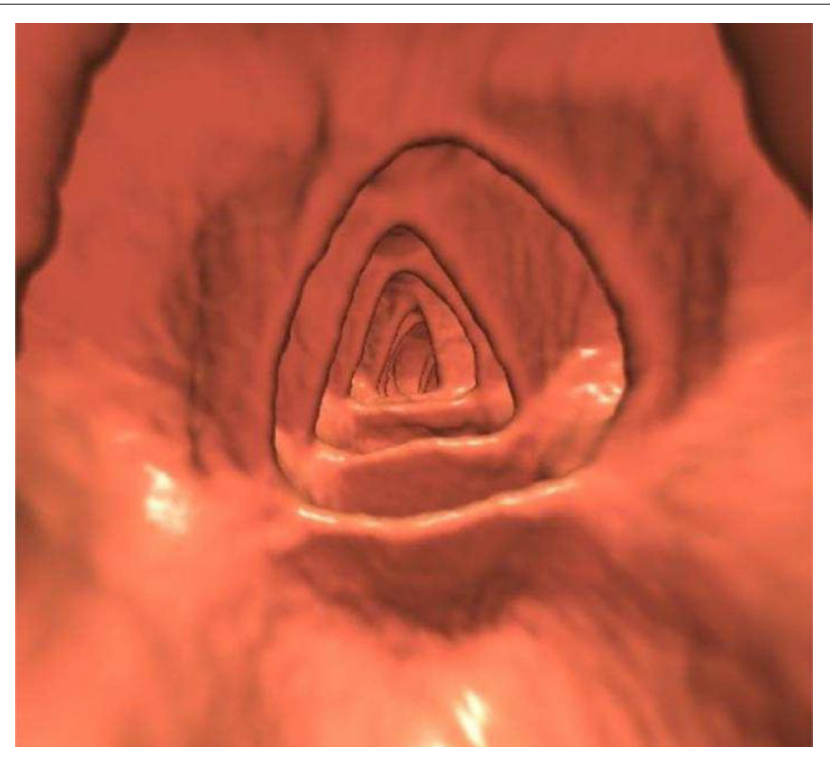

FIGURE 12: Triangular folds in the right colon (caecum to splenic flexure).

TABLE 4: Extracolonic classifications ${ }^{\dagger}$.

\begin{tabular}{|c|c|c|}
\hline Score & Description & Examples \\
\hline $\mathrm{E} 1$ & Normal incidental finding & Retro-aortic $L$ renal vein \\
\hline E2 & Benign conditions & Simple hepatic or renal cyst \\
\hline E3 & $\begin{array}{l}\text { Possibly unimportant/incompletely } \\
\text { characterised - may require further work-up }\end{array}$ & $\begin{array}{l}\text { Complicated renal cysts, prominent cystic adnexal masses in women, indeterminate pulmonary nodules and } \\
\text { indeterminate liver lesions. Caution must be employed when interpreting these lesions as unnecessary work-up will } \\
\text { drive up the overall cost of the screening study }\end{array}$ \\
\hline E4 & Potentially important finding & Large abdominal aortic aneurysm; abdominal mass; lymphadenopathy \\
\hline
\end{tabular}


A centreline is automatically generated and continues in a retrograde fashion to the caecum and ileo-caecal valve. An icon is then clicked which reverses the fly-through from the caecum to the rectum. It takes less than two minutes to perform this bidirectional flight. The same is done in the prone study. The software used by the author allows exceptional visualisation of the bowel lumen for every case by clicking on the 'paint' icon to spray the bowel green. Areas that may not have been visualised (i.e. missed regions) are visualised as pink. To remedy this requires clicking the icon area by area until 100\% visualisation has been achieved. Note that unidirectional fly-through results in only about $90 \%$ coverage of the colon.

A colour-density map is used to assess the density of any protrusions suggestive of polyps or stool that are encountered on the way. Polyps appear as red, barium appears white, and lipomas display as green colouration. The anterior surface of a colon fold faces the rectum and anus; the posterior surface of the fold faces the caecum and ileo-caecal valve (Figure 13). The anterior folds are seen on a retrograde fly-through from the rectum; the posterior ones are seen on the reverse fly-through from the caecum. A 'bookmark' or red dot can be placed on the colon outline to indicate the site of a polyp or carcinoma. The bookmark is useful if a subsequent OC needs to be done. The red dot indicates the site of the lesion as well as the distance from the anal verge (Figure 14). The green line indicates the automated centerline.

How to manage polyps is important. Radiologists need to have a working knowledge of polyp morphology and how to measure polyps, ${ }^{36}$ as well as recommendations to make when polyps are present. It is advisable to include the following disclaimer in all CTC reports: 'CTC is not intended for detection of diminutive polyps ( $\leq 5 \mathrm{~mm}$ ), the presence or absence of which will not change the clinical management of the patient'.

The head of a pedunculated polyp is measured; the length of its stalk is not measured. Polyps of $6 \mathrm{~mm}-9 \mathrm{~mm}$ are termed small. A study is considered positive when a lesion $\geq 6 \mathrm{~mm}$ is detected. If there are more than 3 polyps in the $6 \mathrm{~mm}-9 \mathrm{~mm}$ range, $\mathrm{OC}$ is recommended. If the polyp burden is lower, an option is OC on the same day (Table 3); this will require the study to be read soon after completion of the CTC. A further option is for the patient to be put in a surveillance programme and followed up in three years. If after three years there is an increase in polyp size, the patient can be referred for an OC. Most polyps, however, tend to regress in size. Polyps $\geq 10 \mathrm{~mm}$ are routinely removed. The chance of malignancy is $<1 \%$ in an asymptomatic lowrisk individual. ${ }^{37}$ A summary of classifications of colonic pathology is presented in Table 5. The characteristics of advanced adenomas should be known by radiologists. ${ }^{18,37}$ There are three components to this pathology (Table 6).

More recently, computer-aided diagnosis (CAD) systems have become available. ${ }^{38,39}$ They are of value as either a primary or secondary reader depending on a radiologist's

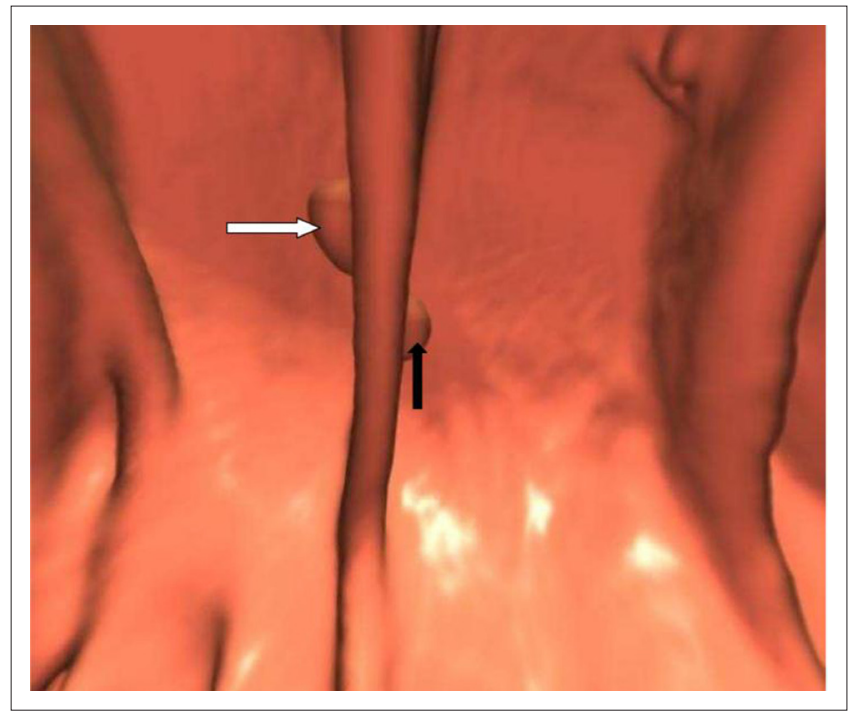

FIGURE 13: Sessile polyp on the posterior haustral fold (white arrow). There is a smaller sessile polyp on the anterior haustral fold (black arrow).

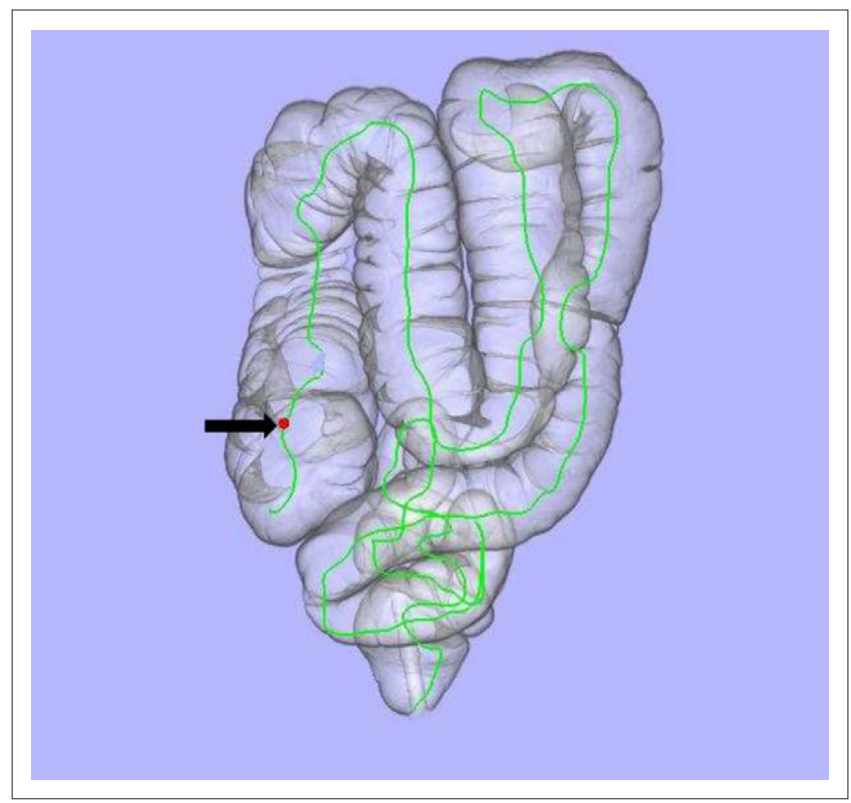

FIGURE 14: Red dot (next to black arrow) indicates lesion site on 3D.

TABLE 5: Colonic classifications ${ }^{\dagger}$

\begin{tabular}{|c|c|c|}
\hline Score & Description & Examples \\
\hline $\mathrm{C1}$ & Normal colon or benign lesion & $\begin{array}{l}\text { - No polyp } \geq 6 \mathrm{~mm} \\
\text { - No visible abnormalities of the colon } \\
\text { - Lipoma or inverted diverticulum }\end{array}$ \\
\hline $\mathrm{C} 2$ & Small polyp & Polyp $6 \mathrm{~mm}-9 \mathrm{~mm}:<3$ in number \\
\hline C3 & $\begin{array}{l}\text { Polyp - possibly advanced } \\
\text { adenoma }\end{array}$ & $\begin{array}{l}\text { - Polyp } \geq 10 \mathrm{~mm} \\
\text { - } \geq 3 \text { polyps (each } 6 \mathrm{~mm}-9 \mathrm{~mm} \text { ) }\end{array}$ \\
\hline $\mathrm{C} 4$ & $\begin{array}{l}\text { Colonic mass (probably } \\
\text { malignant) }\end{array}$ & $\begin{array}{l}\text { Bowel lumen compromised; extracolonic } \\
\text { invasion noted }\end{array}$ \\
\hline
\end{tabular}

, Adapted from Pickhardt PJ, Kim DH. CT colonography: Principles and practice of virtual colonoscopy. Philadelphia: Saunders; 2009; Zalis ME, Barish MA, Choi JR, et al. CT colonography reporting and data system: A consensus proposal. Radiology. 2005;236(1):3-9. http://dx.doi.org/10.1148/radiol.2361041926

TABLE 6: Advanced adenomas ${ }^{\dagger}$.

\section{Criteria for advanced adenomas}

$\geq 10 \mathrm{~mm}$

$>25 \%$ villous present regardless of size

High-grade dysplasia regardless of size

Note: Any one or all 3 criteria may be present

, Adapted from Pickhardt PJ, Kim DH. CT colonography: Principles and practice of virtual colonoscopy. Philadelphia: Saunders; 2009. 
experience. CAD has demonstrated excellent performance for polyp detection in a large screening population undergoing CT colonography with cathartic preparation and oral contrast agent tagging. The combination of high sensitivity for relevant polyps and an acceptable number of false- positive results is very important if CAD is to be implemented clinically. ${ }^{38}$

Given the ongoing technological advances in imaging, new CTC display techniques are also available, such as the 'filet' view where the colon is opened up to view for polyps, or the band view. ${ }^{40}$ These new techniques speed up interpretation time but there is distortion of the mucosal folds, making polyp visualisation difficult.

\section{Concluding remarks}

In a panel discussion in 2006, it was suggested that, within the subsequent five years, CTC would make OC obsolete as the primary colon cancer screening test. ${ }^{41}$ Unfortunately, this prediction has not come to fruition. CTC is a minimally invasive, fast, safe and accurate screening examination for colorectal cancer, ${ }^{1}$ yet $99 \%$ of screening colonoscopies are done via the optical route. In this contested terrain, the referral rate for low-cost screening CTC is dismal. When all the benefits of CTC are presented, ${ }^{2,5,21,42,43}$ patients should be given a choice of deciding to either undergo CTC as the primary screening procedure or therapeutic OC. ${ }^{44}$ A screening CTC study should be undertaken every five years. ${ }^{1,2}$

Regardless of OC's predominance, radiologists need to embrace the new technology, and be prepared and fully trained in all aspects of CTC. This will require making a small investment in a $\mathrm{CO}_{2}$ insufflator as the benefits of $\mathrm{CO}_{2}$ are clearly evident. ${ }^{23}$ What constitutes an adequate number of studies performed before being competent varies and should be contextualised. ${ }^{25,45}$ In countries where CTC is a developing modality, such as in South Africa, the roleplayers should collectively agree on the number of studies that should be performed in order to be competent. CTC is a relatively new procedure that has been validated in the literature. ${ }^{2,6,29,33,36,46}$ It should be part of routine imaging and not a super-specialist examination. There are two aspects to CTC competency: performing the study and interpreting the images. To address both aspects, CME courses could be developed to meet local needs..$^{25,45}$

\section{Acknowledgements}

Professor Perry Pickhardt and Professor David Kim, of the Department of Radiology, University of Wisconsin Medical School, are thanked for their support and sharing their knowledge with me. I am indebted to both of them for advice and guidance for many years as well as always being available for 'second opinions'.

\section{Competing interests}

The author declares that he has no financial or personal relationship(s) that may have inappropriately influenced him in writing this article.

\section{References}

1. American Cancer Society. Cancer facts and figures 2014. [cited 2014 May 20]. Available from: http://www.cancer.org/cancer/colonandrectumcancer/ detailedguide/colorectal-cancer-key-statistics.

2. Yee J, Weinstein S, Morgan T, Alore P, Aslam R. Advances in CT colonography for colorectal cancer screening and diagnosis. J Cancer. 2013:4(3):200-209. http:// colorectal cancer screening and
dx.doi.org/10.7150/jca.5858

3. Siegel R, Naishadbam D, Jemal A. Cancer statistics, 2012. Ca Cancer J Clin 2012;62(1):10-29. http://dx.doi.org/10.3322/caac.20138

4. Muto T, Bussey HJR, Morson BC. The evolution of cancer of the colon and rectum. Cancer. 1975;36(6):2251-2270. http://dx.doi.org/10.1002/cncr.2820360944

5. Pickhardt PJ, Choi R, Hwang I, et al. Computed tomographic virtual colonoscopy to screen for colorectal neoplasia in asymptomatic adults. N Engl J Med. 2003;349(23):2191-2200. http://dx.doi.org/10.1056/NEJMoa031618

6. Kim DH, Hinshaw L, Lubner MG, Munoz de Rio A, Pooler BD, Pickhardt PJ. Contrast coating for the surface of flat polyps at CT colonography: A marker for detection. Eur Radiol. 2014;24(4):940-946. http://dx.doi.org/10.1007/s00330-014-3095-z

7. Adonis L, An R, Luiz J, et al. Provincial screening rates for chronic diseases of lifestyle, cancers and HIV in a health-insured population. S Afr Med J. 2013;103(5):309-312. http://dx.doi.org/10.7196/SAMJ.6686

8. The South African National Cancer Registry 2005. [cited 2014 May 20]. Available from: http://www.cansa.org.za/files/2013/08/Fact-Sheet-Colorecta Cancer-July-2013.pdf

9. Fletcher RH. The end of barium enemas? N Engl J Med. 2000;342(24):1823-1824 (editorial)

10. Ferrucci JT. Double-contrast barium enema: Use in practice and implications for CT colonography. AJR. 2006;187:170-173. http://dx.doi.org/10.2214/ajr.05.0900

11. Chung DJ, Huh KC, Choi WJ, Kim JK. CT colonography using 16-MDCT in the evaluation of colorectal cancer. AJR. 2005;184(1):98-103. http://dx.doi. org/10.2214/ajr.184.1.01840098

12. Veerappan GR, Ally MR, Choi JR, Pak JS, Maydonovitch C, Wong RKH. Extracolonic findings on CT colonography increases yield of colorectal cancer screening. AJR. 2010;195(3):677-686. http://dx.doi.org/10.2214/ajr.09.3779

13. Gluecker $T M$, Johnson $C D$, Wilson $L A$, et al. Extracolonic findings at $C T$ colonography: Evaluation of prevalence and cost in screening population Gastroenterology. 2003;124(4):911-916. http://dx.doi.org/10.1053/gast.2003. 50158

14. Gluecker TM, Johnson CD, Harmsen WS, et al. Colorectal cancer screening with CT colonography, colonoscopy and double-contrast barium enema examination: Prospective assessment of patient perceptions and preferences. Radiology. 2003;227(2):378-384 http://dx.doi.org/10.1148/radiol.2272020293

15. Iqbal CW, Cullinane DC, Schiller HJ, Sawyer MD, Zietlow SP, Farley DR. Surgical management and outcomes of 165 colonoscopic perforations from a single management and outcomes of 165 colonoscopic perforations from a single
institution. Arch Surg. 2008;143(7):701-707. http://dx.doi.org/10.1001/ institution. Arch
archsurg.143.7.701

16. Burling D, Halligan S, Slater A, Noakes MJ, Taylor SA. Potentially serious adverse events at CT colonography in symptomatic patients: national survey of the United Kingdom. Radiology. 2006;239(2):464-471. http://dx/doi.org/10.1148/ radiol.2392051101

17. Pickhardt PJ. Screening CT colonography: How I do it. AJR. 2007;189(2):290-298. http://dx.doi.org/10.2214/ajr.07.2136

18. Pickhardt PJ, Kim DH. CT colonography: Principles and practice of virtua colonoscopy. Philadelphia: Saunders; 2009.

19. Summers R. The elephant in the room: Bowel preparation for CT colonography. Acad Radiol. 2009;16(7):777-779. http://dx.doi.org/10.1016/j.acra.2009.04.001

20. Hara AK, Kuo MD, Blevins $M$, et al. National CT colonography trial (ACRIN 6664): Comparison of three full-laxative bowel preparations in more than 2500 average-risk patients. AJR. 2011;196(5):1076-1082 http://dx.doi.org/10.2214/ AJR.10.4334

21. Dachman AH. Advice for optimising colonic distention and minimizing risk of perforation during CT colonography. Radiology. 2006;239(2):317-321.

22. Sosna J, Bar-Ziv J, Libson E, Eligulashvili M, Blachar A. CT colonography: Positioning order and intracolonic pressure. AJR. 2008;191(4):W175-W180. http://dx.doi.org/10.2214/ajr.07.3303

23. Burling D, Taylor SA, Halligan S, et al. Automated insufflation of carbon dioxide for MDCT colonography: Distension and patient experience compared with manual insufflation. AJR. 2006;186(1):96-103. http://dx.doi.org/10.2214/ajr.04.1506

24. Shinners TJ, Pickhardt PJ, Taylor AJ, Jones DA, Olsen CH. Patient-controlled room air insufflation versus automated carbon dioxide delivery for CT colonography. AJR. 2006;186(6):1491-1496. http://dx.doi.org/10.2214/ajr.05.0416

25. American College of Radiology. ACR practice guideline for the performance of computed tomography (CT) colonography in adults. Revised 2009. [cited 2014 March 01]. Available from: http://www.acr.org/ /media/ACR/Documents/PGTS/ guidelines/CT_Colonography.pdf

26. Talati RK, Dunkin J, Parikh S, Moore WH. Current methods of monitoring radiation exposure from CT. J Am Coll Radiol. 2013;10(9):702-707. http://dx.doi. org/10.1016/j.jacr.2013.03.002

27. Raman SP, Johnson PT, Deshmukh S, Mahesh M, Grant KL, Fishman EK. CT dose reduction applications: Available tools on the latest generation of CT scanners. J Am Col Radiol. 2013;10(1):37-41. http://dx.doi.org/10.1016/j.jacr.2012.06.025

28. Brenner DJ, Georgsson MA. Mass screening with CT colonography: Should radiation exposure be of concern? Gastroenterology. 2005;129(1):328-337. http://dx.doi.org/10.1053/j.gastro.2005.05.021 
29. Levin B, Lieberman DA, McFarland B, et al. Screening and surveillance for the early detection of colorectal cancer and adenomatous polyps, 2008: A joint guideline from the American Cancer Society, the US multi-society task force 2008;58(3):130-160. http://dx.doi.org/10.3322/CA.2007.0018

30. Hough DM, Kuntz MA, Fidler JL, et al. Detection of occult colonic perforation before CT colonography after incomplete colonoscopy: Perforation rate and use of a lowdose diagnostic scan before $\mathrm{CO}_{2}$ insufflation. AJR. 2008;191(4):1077-1081. http:// dx.doi.org/10.2214/ajr.07.2746

31. Copel L, Sosna J, Kruskal JB, Raptopoulos V, Fareell RJ, Morrin MM. CT colonography in 546 patients with incomplete colonoscopy. Radiology. 2007;244(2):471-478.

32. Zalis ME, Barish MA, Choi JR, et al. CT colonography reporting and data system: A consensus proposal. Radiology. 2005;236(1):3-9. http://dx.doi.org/10.1148/ radiol.2361041926

33. Pickhardt PJ, Taylor AJ. Extracolonic findings identified in asymptomatic adults at screening CT colonography. AJR. 2006;186(3):718-728. http://dx.doi.org/10.2214/ ajr.04.1748

34. Pickhardt PJ, Kim DH, Meiners RJ, et al. Colorectal and extracolonic cancers detected at screening CT colonography in 10286 asymptomatic adults. Radiology. 2010;255(1):83-88. http://dx.doi.org/10.1148/radiol.09090939

35. Pickhardt PJ, Lee AD, Taylor AJ, et al. Primary 2D versus primary 3D polyp detection at screening CT colonography. AJR. 2007;189(6):1451-1456. http://dx.doi org/10.2214/ajr.07.2291

36. Pickhardt PJ, Kim DH. Colorectal cancer screening with CT colonography: Key concepts regarding polyp prevalence, size, histology, morphology, and natura history. AJR. 2009;193(1):40-46. http://dx.doi.org/10.2214/aj.08.1709

37. Johnson CD, Chen M, Toledano AY, et al. Accuracy of CT colonography for detection of large adenomas and cancers. N Engl J Med. 2008;359(12):1207-1217. http:// dx.doi.org/NEJMoa0800996

38. Lawrence EM, Pickhardt PJ, Kim DH, Robbins JB. Colorectal polyps: Stand-alone performance of computer-aided detection in a large asymptomatic screening population. Radiology. 2010;256(3): 791-798. http://dx.doi.org/10.1148/ radiol.10092292
39. Halligan S, Mallett $S$, Altman DG, et al. Incremental benefit of computer-aided detection when used as a second and concurrent reader of CT colonographic data: Multiobserver study. Radiology. 2011;258(2):469-476. http://dx.doi. org/10.1148/radiol.10100354

40. Lee SS, Park SH, Kim JK, et al. Panoramic endoluminal display with minimal image distortion using circumferential radial ray-casting for primary three-dimensional interpretation of CT colonography. Eur Radiol. 2009;19(8):1951-1959. http:// interpretation of CT colonography. Eur
dx.doi.org/10.1007/s00330-009-1362-1

41. Yoshida $\mathrm{H}$, Svoboda AC. Within the next five years $\mathrm{CT}$ colonography will make conventional colonoscopy obsolete for colon cancer screening. In: Orton CG, Hendee WR, editors. Controversies in medical physics: A compendium of Hendee WR, editors. Controversies in medical physics: A compendium of
point/counterpoint debates. Maryland: American Association of Physicists point/counterpoint debates. Maryland: American Association of Physicists PointCounterpointCompedium.pdf\#page $=245$

42. Perisinakis K, Seimenis I, Tzedakis A, Papadakis A, Kourinou K, Damilakis J. Screening computed tomography colonography with 256-slice scanning: Should patient radiation burden and associated cancer risk constitute a majo concern? Invest Radiol. 2012;47(8):451-456. http://dx.doi.org/10.1097/ RLI.0b013e318250a58c

43. Gonzalez AM, Kim KP, Yee J. CT colonography: Perforation rates and potentia radiation risks. Gastrointest Endosc Clin N Am. 2010;20(2):279-291. http:// dx.doi.org/10.1016/j.giec.2010.02.003

44. Kim DH, Pickhardt PJ, Taylor AJ, et al. CT colonography versus colonoscopy for the detection of advanced neoplasia. N Engl J Med. 2007;357(14):1403-1412. http:// dx.doi.org/10.1056/NEJMoa070543

45. Fletcher JG, Chen M, Herman BA, et al. Can radiologist training and testing ensure high performance in CT colonography? Lessons from the national CT colonography trial. AJR. 2010;195(1):117-125. http://dx.doi.org/10.2214/ ajr.09.3659

46. Yee J, Keysor KJ, Kim DH. The time has arrived for national reimbursement of screening CT colonography. AJR. 2013;201(1):73-79. http://dx.doi.org/ ajr.13.10656 